\title{
Characterization tests for predicting the mechanical performance of SFRC floors: identification of fibre distribution and orientation effects
}

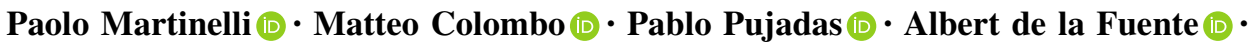 \\ Sergio Cavalaro $($ id $\cdot$ Marco di Prisco $(1)$
}

Received: 28 March 2020/ Accepted: 27 November 2020/Published online: 5 January 2021

(C) The Author(s) 2020

\begin{abstract}
In the context of the evaluation of the loadbearing capacity of a steel fibre reinforced concrete (SFRC) elevated slab recently built in northern Italy, this paper presents the study addressing the effects of fibre distribution and orientation. An extensive experimental programme was carried out in a collaboration between Politecnico di Milano and Universitat Politècnica de Catalunya. The programme included mechanical tests on four shallow beams and six notched standard beams. Additionally, uniaxial tensile tests (UTTs), double edge wedge splitting tests (DEWSTs) and double punching tests (DPTs) on 192 drilled core samples extracted from the shallow beams were performed. Inductive tests,
\end{abstract}

P. Martinelli $(\bowtie) \cdot$ M. Colombo · M. di Prisco

Department of Civil and Environmental Engineering,

Politecnico di Milano, P.za L. da Vinci 32, 20133 Milan, Italy

e-mail: paolo.martinelli@polimi.it

P. Pujadas

Department of Project and Construction Engineering, Universitat Politècnica de Catalunya (UPC), Av. Diagonal 647, 08028 Barcelona, Spain

A. de la Fuente

Department of Civil and Environmental Engineering, Universitat Politècnica de Catalunya (UPC), Jordi Girona 1-3, 08034 Barcelona, Spain

S. Cavalaro

School of Architecture, Building and Civil Engineering, Loughborough University, Sir Frank Gibb Building RT102, Loughborough, UK measuring the self-induction change that occurs when a SFRC sample is placed inside a coil, were performed on all samples subjected to DPTs to assess fibre distribution. This paper compares direct and indirect tensile tests for the definition of the FRC post-cracking constitutive law, highlighting advantages and disadvantages of each test type. A comparison between standard and nonstandard mechanical tests is also presented. Mechanical and non-destructive tests on drilled core samples extracted in different directions and at different locations have allowed the evaluation of the effects of fibre distribution and fibre orientation which provide an estimation of the possibility of using these tests as simplified tests for production control.

Keywords Fibre reinforced concrete (FRC) . Control production tests - Fibre distribution - Fibre orientation - Uniaxial tensile test (UTT) · Double edge wedge splitting test (DEWST) - Double punching test (DPT)

\section{Introduction}

A two-storey family house was recently built in northern Italy using a steel fibre reinforced concrete (SFRC) elevated slab. The building consisted of a $290 \mathrm{~m}^{2}$ underground SFRC foundation slab with a thickness of $400 \mathrm{~mm}$, and a $240 \mathrm{~m}^{2}$ SFRC elevated 
slab at ground level with a thickness of $250 \mathrm{~mm}$. Concurrently with the SFRC slab casting, 4 shallow beams $\left(1.5 \times 0.5 \times 0.25 \mathrm{~m}^{3}\right)$ with the same thickness as the slab were cast. In order to verify the specific load-bearing capacity of the slab, shallow beams were tested following a bending test set-up. The FRC material was classified based on postcracking residual stress by testing six standard notched specimens $\left(0.55 \times 0.15 \times 0.15 \mathrm{~m}^{3}\right)$ using a three-point bending test according to [1]. Cylindrical samples were cored from the shallow beams, cut and tested using 3 characterization tests: uniaxial tensile test (UTT), double edge wedge splitting test (DEWST) [2] and double punching test (DPT) [3]. In the closely-linked study [4], results obtained from these 3 tests were presented separately, to highlight which would be more suitable for defining the postcracking constitutive law.

The enhanced post-cracking behaviour of FRC is particularly influenced by the amount of fibres effectively crossing a crack and its bond and strength properties [5]. Since not all fibres can be aligned in the direction of the applied stress, the fibres' effectiveness depends on the loading conditions (mainly on the directions of the principal tensile stresses) and the fibre orientation in relation to the active crack plane. Thereby, as proposed in the fib Model Code 2010 [6] the consideration of fibre orientation and dispersion is of great interest in FRC design, as they significantly affect the post-cracking mechanical properties of the material [7-10]. Thus, the objective of this study is to compare the post-cracking constitutive law derived from the different tests, providing a discussion of their advantages and disadvantages. The paper also examines the effects of fibre distribution and orientation on the post-cracking mechanical performance, obtained by means of inductive testing of cores extracted in different directions and positions.

\section{Experimental research}

A detailed description of the entire experimental programme is reported in the related study [4]; only the details required to understand the results reported in the sections that follow are recalled briefly.

\subsection{Material characteristics and mechanical characterization}

The SFRC adopted in the experimental programme has a density equal to $2358 \mathrm{~kg} / \mathrm{m}^{3}$. The material mix design is specified in [4]. The composition was designed for a target compressive strength C28/35 (where 28 represents the cylindrical and 35 the cubic compressive strength) and a S5 workability class according to the Italian code [11]. The fibres used in the mix are low-carbon cut-sheet indented steel fibre, $60 \mathrm{~mm}$ long with an aspect ratio $\left(l_{\mathrm{f}} / d_{\mathrm{f}}\right)$ equal to 60 and a tensile strength higher than $1200 \mathrm{MPa}$. A fibre content equal to $35 \mathrm{~kg} / \mathrm{m}^{3}$ ( $0.44 \%$ by volume) was used. The compressive strength of seven cubes (150$\mathrm{mm}$-sided) were determined at 28 days, getting a cubic mean compressive strength equal to $55.6 \mathrm{MPa}$ and a coefficient of variation (CV) equal to $4.78 \%$.

The post-cracking material tensile behaviour was evaluated according to [1] by using a three-point bending test (3PBT) on specimens with a crosssection of $150 \times 150 \mathrm{~mm}^{2}$ with a $25 \mathrm{~mm}$ deep notch and a span of $500 \mathrm{~mm}$. Details on the 3PBT loading protocol are given in [4]. The limit of proportionality $f_{\mathrm{LOP}}$, and the residual flexural tensile strengths $f_{\mathrm{R} 1}, f_{\mathrm{R} 2}$, $f_{\mathrm{R} 3}$ and $f_{\mathrm{R} 4}$ for a crack mouth opening displacement (CMOD) of $0.5,1.5,2.5$ and $3.5 \mathrm{~mm}$, respectively, were measured for all the specimens. The average and characteristic values are reported in Table 1. The material was classified according to fib Model Code 2010 specifications [6] and denoted as " $2.5 \mathrm{c}$ " with reference to the characteristic values.

\subsection{Experimental procedure for the evaluation} of non-standardized tests

Four nominally identical SFRC shallow beams $1.5 \mathrm{~m}$ long with a rectangular cross-section equal to

Table 1 Three-point bending test results: nominal strengths $f_{\mathrm{LOP}}, f_{\mathrm{R} 1}, f_{\mathrm{R} 2}, f_{\mathrm{R} 3}$ and $f_{\mathrm{R} 4}$ according to EN 14651 [1]

\begin{tabular}{llllll}
\hline Reference values & $\begin{array}{l}f_{\mathrm{LOP}} \\
(\mathrm{MPa})\end{array}$ & $\begin{array}{l}f_{\mathrm{R} 1} \\
(\mathrm{MPa})\end{array}$ & $\begin{array}{l}f_{\mathrm{R} 2} \\
(\mathrm{MPa})\end{array}$ & $\begin{array}{l}f_{\mathrm{R} 3} \\
(\mathrm{MPa})\end{array}$ & $\begin{array}{l}f_{\mathrm{R} 4} \\
(\mathrm{MPa})\end{array}$ \\
\hline Mean $\left(m_{\mathrm{x}}\right)$ & 5.52 & 4.78 & 4.63 & 4.06 & 3.65 \\
$\mathrm{SD}\left(s_{\mathrm{x}}\right)$ & 0.30 & 1.02 & 1.01 & 0.78 & 0.67 \\
$f_{\mathrm{k}}($ normal) & 4.87 & 2.57 & 2.43 & 2.37 & 2.19 \\
$f_{\mathrm{k}}(\log$-normal) & 4.88 & 2.99 & 2.79 & 2.56 & 2.35 \\
\hline
\end{tabular}


$500 \times 250 \mathrm{~mm}^{2}$ were formed on the same day as the elevated slab was cast and tested in a four-point bending test set-up. The shallow beams were named A, B, E, F, respectively. The set-up of the shallow beam test and related results can be found in [4].

Uniaxial tensile tests (UTTs), double edge wedge splitting tests (DEWSTs) and double punching tests (DPTs) were performed on 192 drilled core samples extracted from the shallow beams after the bending tests. UTTs were performed with rotating end-platens, while DEWSTs and DPTs followed the procedures defined in [2] and [3], respectively. The tests were instrumental to evaluate (a) the tests' representativeness as discussed in the closely-linked study [4] and (b) the effect of fibre distribution and orientation as discussed later in this paper.

\subsubsection{Core drilling strategy}

Drilled cores are essential for studying the influence of fibre distribution and orientation on the mechanical performance even though they introduce a significant reduction of the fibre anchorage close to the external cylindrical face, especially if fibres are long in relation to the core diameter and end-indented. After testing the shallow beams, 48 cylinders with a diameter of $100 \mathrm{~mm}$ were cored from the four beams along $x$-, $y$ and $z$-directions in the uncracked zones (Figs. 1 and 2). Cylinders cored along the $z$-axis have a length of $250 \mathrm{~mm}$ corresponding to the beam thickness, while cylinders cored from the $x$ - and $y$-directions have a length of $400 \mathrm{~mm}$. Shallow beams E and F were cored in the $z$-direction (Fig. 1), while beams A and B were cored in the $x$ - and $y$-directions (Fig. 2).

Specimens used for UTTs and DPTs were obtained by cutting cylinders cored in the $z$-direction into two equal parts and cylinders cored in the $x$ - and $y$ directions into three equal parts resulting in cylinder with a height equal to $100 \mathrm{~mm}$. Specimens for DEWSTs were obtained by cutting cylinders cored in the $z$-direction into four equal parts and cylinders cored in the $x$ - and $y$-directions into six equal parts resulting in cylinder with a height of $50 \mathrm{~mm}$ (Figs. 1 and 2). The total number of samples after the drilling and cutting operations was 192, where 24 specimens (12 $x$-dir. $+12 y$-dir.) were subjected to the UTT, 112 specimens $(24 x$-dir. $+24 y$-dir. $+64 z$-dir. $)$ were subjected to the DEWST and 56 specimens (12 $x$-dir. $+12 y$-dir. $+32 z$-dir.) were subjected to the DPT. The nomenclature adopted to refer to specimens starts with a letter indicating the cored beam followed by a progressive number indicating the position in the beam. For samples cored in the $z$-direction, another term was appended at the end of the nomenclature to identify the position of the specimen in terms of the height of the core before the cutting process ("Top", "Mid-Top", "Mid-Bot." or "Bot." for specimens subjected to DEWST and "Top", and "Bot." for specimens subjected to UTT or DPT as depicted in Fig. 1). With reference to DEWST, the dotted lines in Figs. 1 and 2 indicate the orientation of the fracture planes.

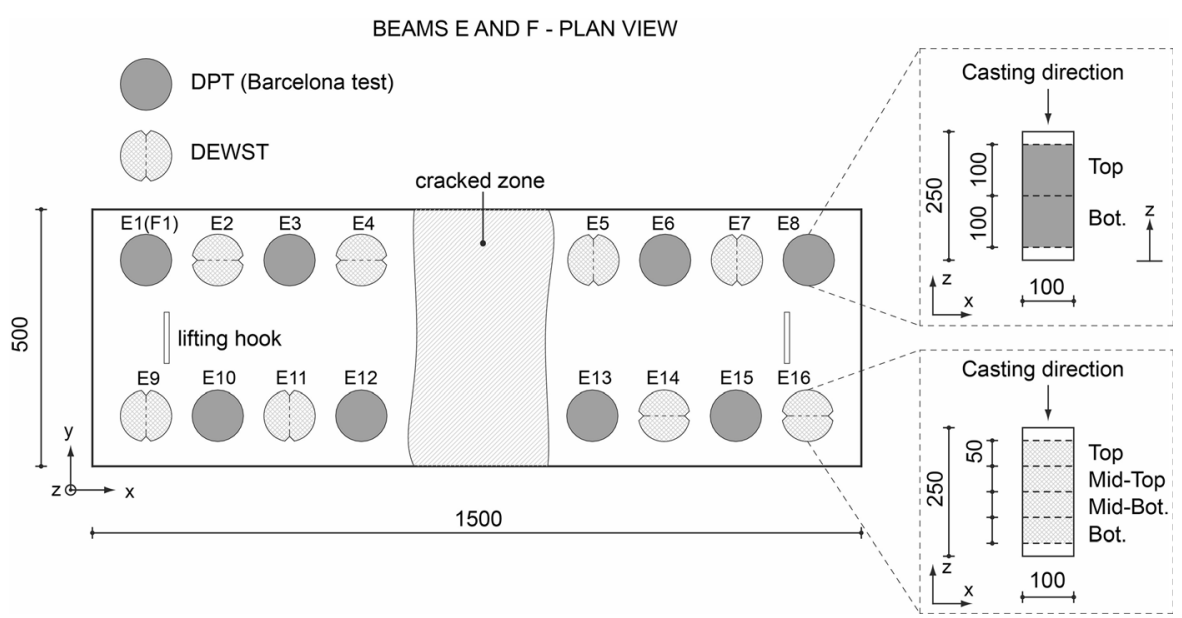

Fig. 1 Position and size of the cylindrical cores extracted from shallow beams $\mathrm{E}$ and $\mathrm{F}$ (dimensions in $\mathrm{mm}$ ) 
BEAM A - PLAN VIEW

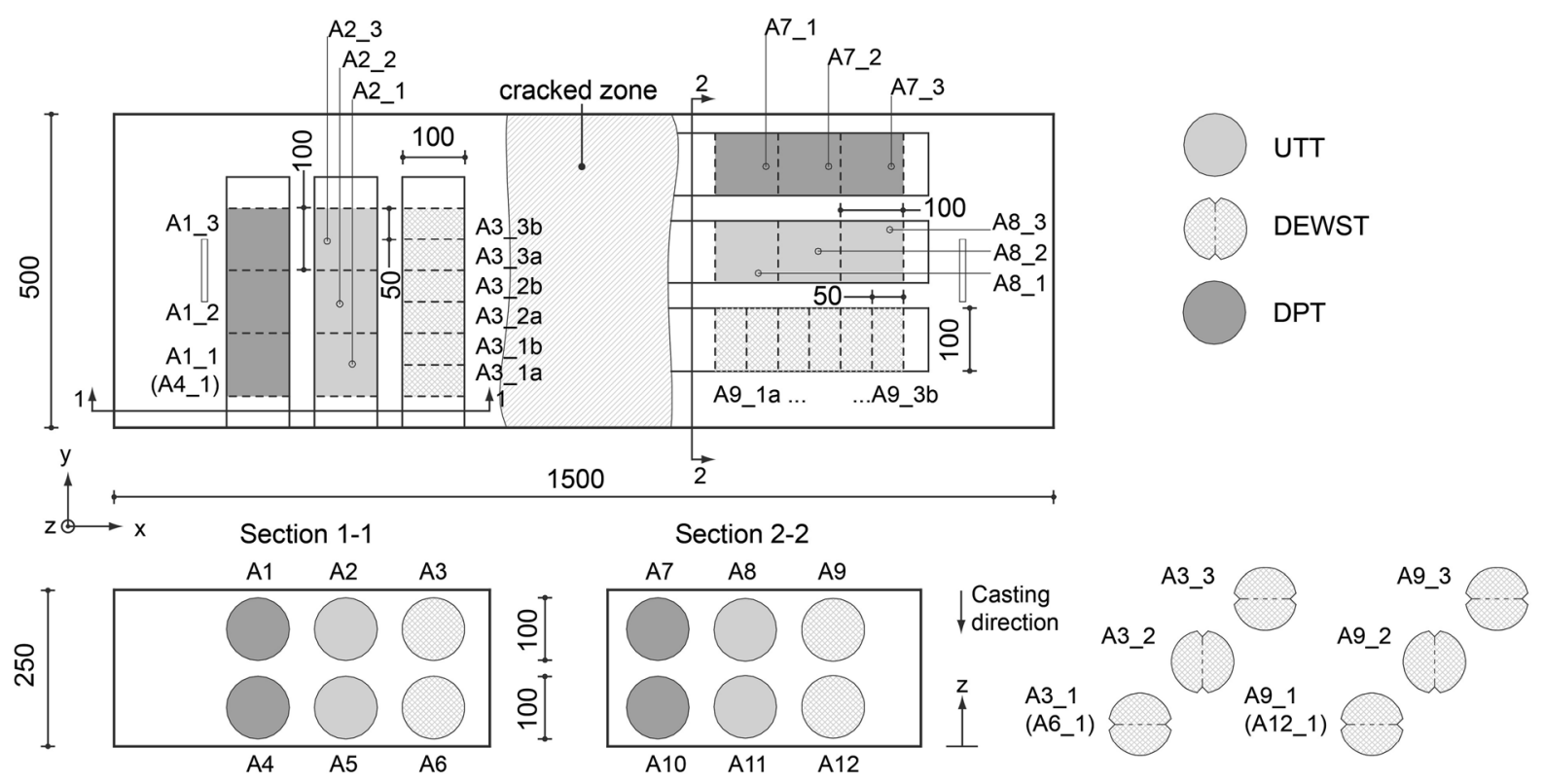

BEAM B - PLAN VIEW
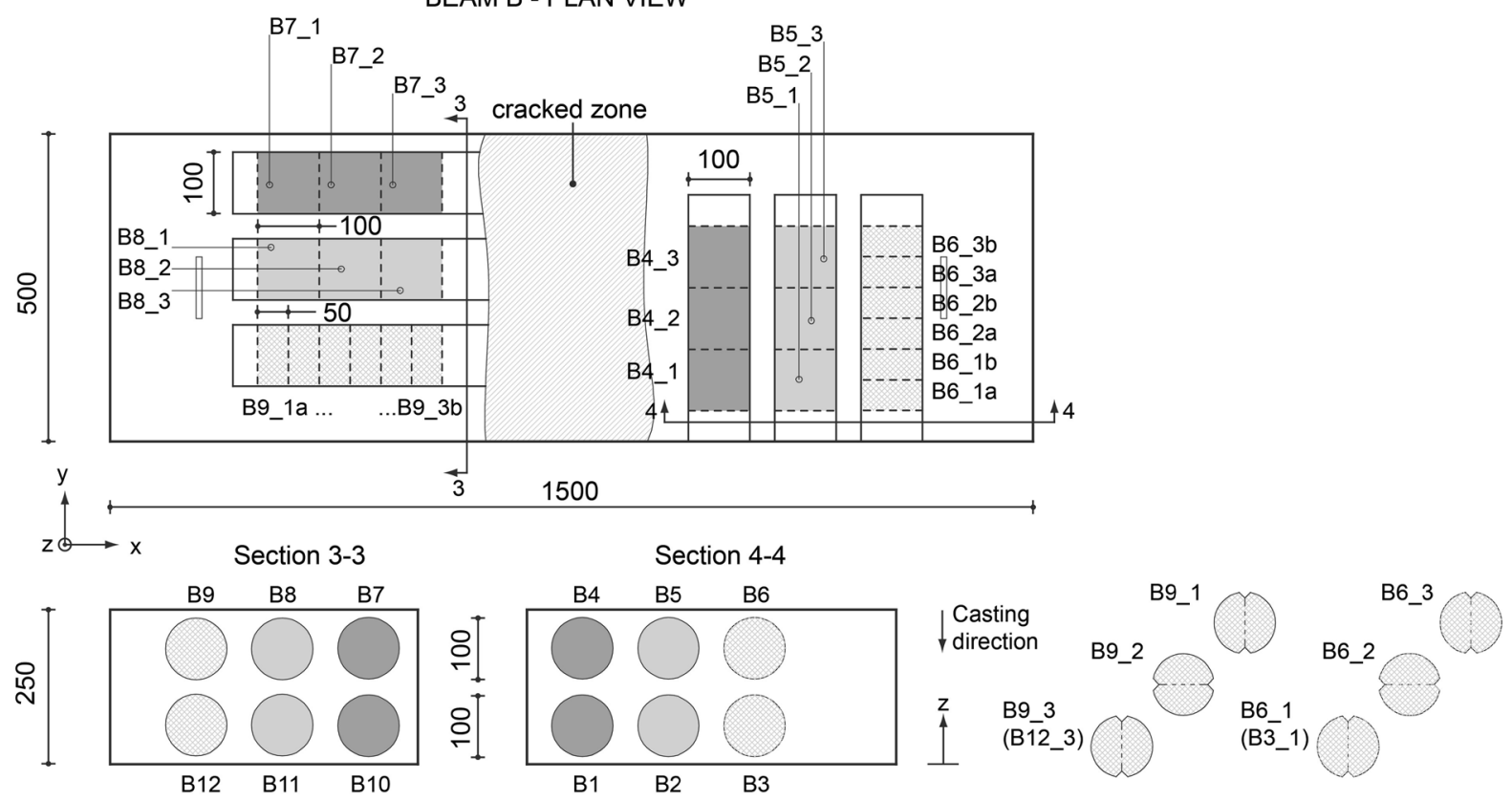

Fig. 2 Position and size of the cylindrical cores extracted from shallow beams A and B (dimensions in mm)

\subsubsection{UTT, DEWST and DPT: specimens' geometry, size and test set-up}

Figure 3 depicts the specimens' geometries, sizes and test set-up for three characterization tests (i.e. UTT, DEWST and DPT). With reference to UTT and
DEWST notching details are also shown in Fig. 3. The UTTs were carried out at Politecnico di Milano using an electromechanical press (Instron 8562) with a nominal capacity of $100 \mathrm{kN}$ and a precision equal to $0.5 \%$. The rotating end-platens solution was adopted to conduct the UTTs following the procedure described by 

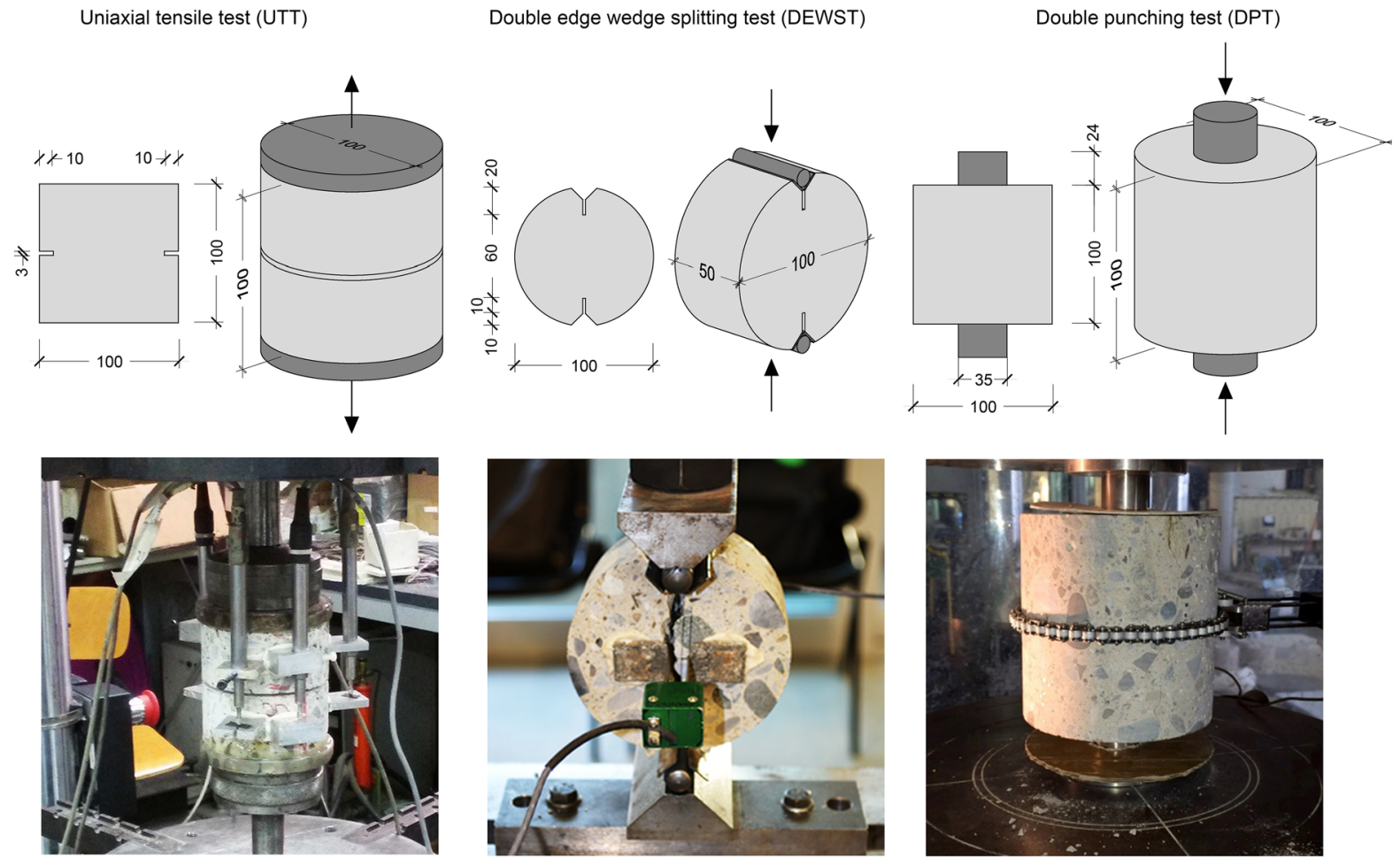

Fig. 3 Specimen dimensions in mm and test set-ups for uniaxial tensile test (UTT, left), double edge wedge splitting test (DEWST, middle) and double punching test (DPT or Barcelona test, right)

[12] among others; with this solution the system prevents a bending moment being transferred to the specimen but, on the contrary, does not allow a uniform crack opening along the notched cracked cross-section. UTTs were carried out under mean crack opening dispalcement (COD) control, obtained as the average COD from two Linear Variable Displacement Transducers (LVDTs) placed astride the notch around the cylindrical specimen at $180^{\circ}$ from each other. The two LVDTs were electrically connected in parallel to obtain an average signal used as the feedback parameter. Three additional LVDTs were placed radially at $120^{\circ}$ astride the notch to fully describe the specimen's response.

The DEWSTs were carried out at Politecnico di Milano under displacement control using an electromechanical press (Instron 5867) with a nominal capacity of $30 \mathrm{kN}$ and a precision equal to $0.4 \%$. The crack propagation was detected through two LVDTs placed at the mid-height of the specimen on the front and rear sides.

The DPTs were carried out at the Universitat Politècnica de Catalunya using a hydraulic press (Ibertest) and a circumferential chain to measure the total crack opening displacement (TCOD). The tests were performed under stroke control by placing two cylindrical steel punches $(24 \mathrm{~mm}$ in height and with a diameter of $35 \mathrm{~mm}$ ) concentrically above and below the specimens. A full description of the instrumentation and loading rates adopted for the three characterization tests is given in [4].

\section{UTT, DEWST and DPT comparison}

This section compares the direct and indirect tensile tests described in the previous section for the definition of the FRC post-cracking constitutive law. Figure 4 shows the average experimental results for the specimens tested under UTT, DEWST and DPT in terms of nominal stress $\left(\sigma_{\mathrm{N}}\right)$ versus COD. The description on how the original rough data was transformed into stress $\sigma_{\mathrm{N}}-\mathrm{COD}$ for the three characterization tests can be found in [4]. Figure 4 includes all specimens tested without any distinction in terms of the direction or position from which the core was extracted in relation to the cracked plane. The total number of samples tested $\left(n_{\mathrm{s}}\right)$ with UTT, 


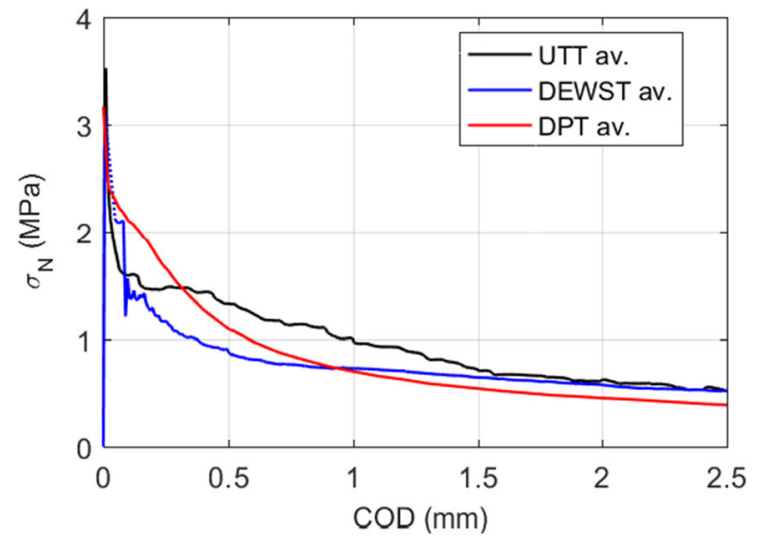

Fig. 4 Nominal stress versus COD from UTTs, DEWSTs and DPTs: average values

DEWST and DPT is equal to 11,80 and 53 respectively. The total number of specimens successfully tested is less than the number of specimens extracted from the beams and equal to 24, 112 and 56 for UTT, DEWST and DPT, respectively. The reason is that several samples were lost at the beginning of the experimental campaign before optimization of the UTT and DEWST set-ups. The figure shows that DEWST results align with UTT results for both the pre- and post-cracking stages. The DEWST provides an average slightly smaller than UTT in CODs up to $1.5 \mathrm{~mm}$. The DPT method shows the highest energy dissipation for CODs up to about $0.3 \mathrm{~mm}$. This result is related to the spurious energy due to the formation of the conical wedge [13] for low values of CODs. When the specimen's response is governed by the debonding and pull-out of the fibres, UTT, DEWST and DPT provide similar results (in Fig. 4 for CODs larger than $1.5 \mathrm{~mm})$.

Figure 5 shows the $\sigma_{\mathrm{N}}$ versus COD for specimens with a fracture plane orthogonal to the $x$-axis (length of the shallow beam), which should be better correlated with the cracking and bending capacity of the shallow beams. It is important to note that for DPTs, the fracture planes are not necessarily orthogonal to the $x$ axis of the beam, and the only specimens excluded are those cored along the $x$-axis (see Figs. 1 and 2). Findings largely agree with those described in the previous paragraph for Fig. 4. A greater response difference between the three methods is visible for CODs greater than $1.5 \mathrm{~mm}$ compared to what is shown in Fig. 4 partly due to the lower number of specimens considered. Table 2 summarises the average tensile

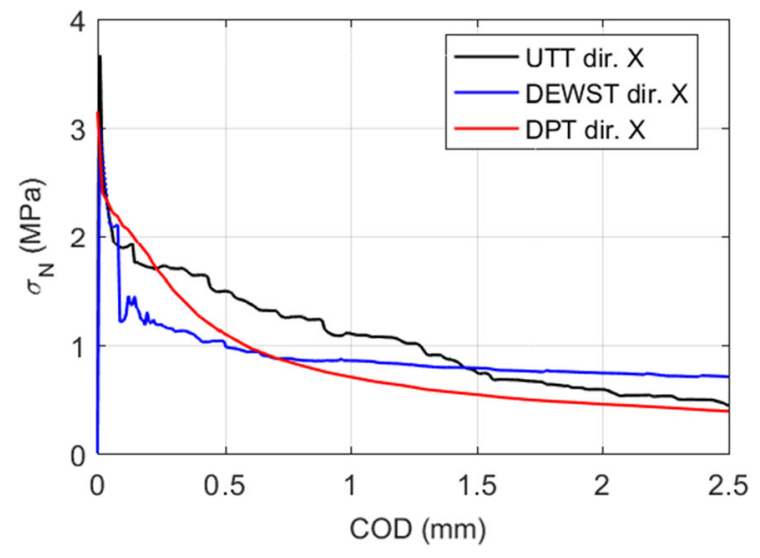

Fig. 5 Nominal stress versus COD from UTTs, DEWSTs and DPTs for samples with the cracked plane orthogonal to the beam's $x$-axis

peak strength $f_{\text {ct }}$ and the corresponding coefficient of variation from the UTT, DEWST and DPT results. The table also reports the average residual strength for CODs equal to $0.5,1.5$ and $2.5 \mathrm{~mm}$ and the corresponding CVs. It is interesting to observe how the splitting tests (DEWST and DPT) result in a tensile strength 20\% lower than UTT: the main factor has to be looked for in a significant loss of fibre anchorage due to geometrical reasons easily identified when looking at the cracked planes in the three different characterization tests. Another reason should be sought in the different crack propagation that involves a significantly reduced redistribution.

\section{Influence of fibre orientation and distribution}

Several authors have shown the direct influence of the orientation of the fibres on the residual strength of the material [7, 9, 14]. Studies have shown that an anisotropic orientation of fibres in the hardened state may occur as a result of the different stages and processes (fresh state, concrete pouring, geometry of the formwork, type of vibration and production method) that FRC undergoes from mixing to hardening $[15,16]$.

\subsection{Fibre distribution}

An important aspect related to the distribution of fibres and dependent on casting of the FRC element is possible fibre segregation, which has been reported in 
Table 2 Average nominal strengths $f_{\mathrm{ct}}, f_{\mathrm{R} 0.5}, f_{\mathrm{R} 1.5}$, and $f_{\mathrm{R} 2.5}$ for UTTs, DEWSTs and DPTs (in brackets CV \%)

\begin{tabular}{lllll}
\hline Test type (number of tests) & $\begin{array}{l}f_{\mathrm{ct}} \\
(\mathrm{MPa})\end{array}$ & $\begin{array}{l}f_{\mathrm{R} 0.5} \\
(\mathrm{MPa})\end{array}$ & $\begin{array}{l}f_{\mathrm{R} 1.5} \\
(\mathrm{MPa})\end{array}$ & $\begin{array}{l}f_{\mathrm{R} 2.5} \\
(\mathrm{MPa})\end{array}$ \\
\hline $\operatorname{UTT}\left(n_{\mathrm{s}}=7\right)$ & $3.67(7.73 \%)$ & $1.49(48.0 \%)$ & $0.74(36.7 \%)$ & $0.44(34.2 \%)$ \\
$\operatorname{DEWST}\left(n_{\mathrm{s}}=30\right)$ & $3.00(19.2 \%)$ & $1.03(47.9 \%)$ & $0.78(58.7 \%)$ & $0.71(65.6 \%)$ \\
$\operatorname{DPT}\left(n_{\mathrm{s}}=41\right)$ & $3.15(5.07 \%)$ & $1.10(24.6 \%)$ & $0.54(33.1 \%)$ & $0.39(40.6 \%)$ \\
\hline
\end{tabular}

elevated slabs by [17]. This effect is relevant as the mechanical properties of FRC due to the effectiveness of the fibres depends on the number and the orientation of the fibres. Generally, the residual tensile strength increases with an increase in the number of fibres.

Fibre segregation is analysed by considering the specimens cored along the thickness (z-direction) and comparing specimens that lie above ("Top" and "Mid-Top" for specimens subjected to DEWST or "Top" for specimens subjected to DPT) or below ("Bot." and "Mid-Bot." for specimens subjected to DEWST or "Bot." for specimens subjected to DPT) the middle plane. Figure 6 compares the average $\sigma_{\mathrm{N}}$ versus COD curves for "Top"/"Mid-Top" and "Bot."/"Mid-Bot." specimens tested using DPT $\left(n_{\mathrm{s}}=29\right)$ and DEWST $\left(n_{\mathrm{s}}=51\right)$. Specimens in contact with the formwork show a higher post-cracking stress than those closer to the surface, which is confirmed both in DPT and DEWST results. In particular, for CODs equal to $0.5 \mathrm{~mm}$, "Bot."/"MidBot." specimens tested with DEWST and DPT show a nominal stress 30\% higher than "Top"/"Mid-Top"

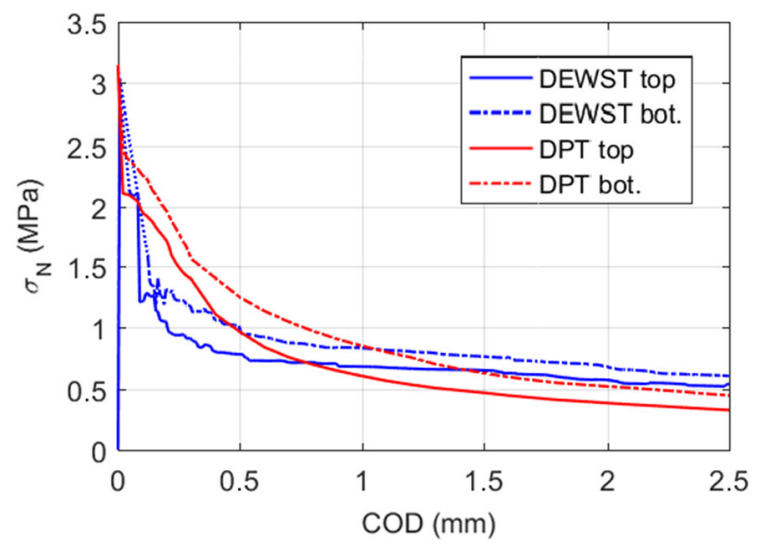

Fig. 6 Influence of the specimen's position in the thickness direction in terms of nominal stress versus COD for the DEWSTs and DPTs (top = casting side; bot. = formwork side) specimens. This difference decreases to $13 \%$ for CODs equal to $2.5 \mathrm{~mm}$ in DEWST specimens.

Two factors may have influenced the results: (a) fibre content and (b) fibre orientation. Since only point (a) is related to fibre segregation, the mechanical results shown in Fig. 6 are not enough to conclude that fibre segregation takes place.

In order to clarify and corroborate the previous results, Fig. 7 summarizes the number of fibres $n_{\mathrm{f}}$ counted on the net cross-section surface of the 51 DEWST specimens cored along the $z$-axis. The figure breaks down the position of the specimens over the slab thickness into the four positions ("Top", "Mid-Top", "Mid-Bot." and "Bot.", see Fig. 1). For each of these, the figure shows the average $n_{\mathrm{f}}$ values with a black circular marker. The theoretical number of fibres $n_{\mathrm{f}, \mathrm{t}}$ calculated on the net cross-section surface using the well-known expression provided by [18], is

$n_{\mathrm{f}, \mathrm{t}}=\alpha \frac{V_{\mathrm{f}}}{A_{\mathrm{f}}} A_{\text {lig }}$

The term $\alpha$ in Eq. (1) represents the orientation factor, $V_{\mathrm{f}}$ represents the volume fraction of steel fibres,

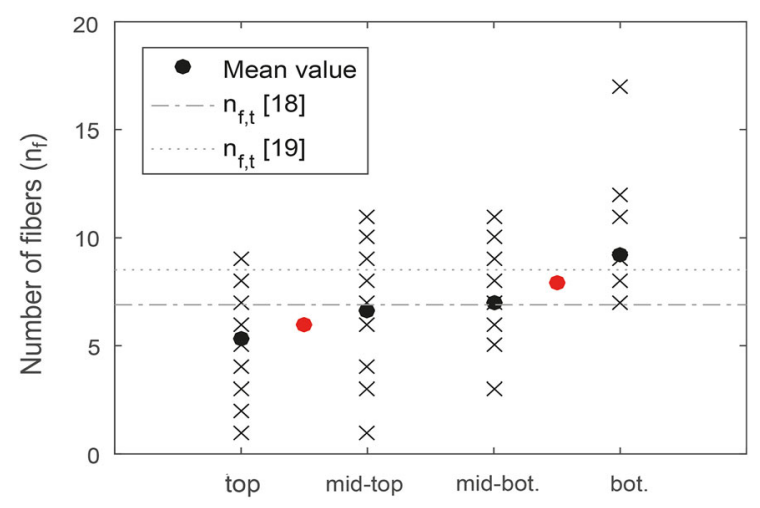

Fig. 7 Influence of DEWST specimen position within the thickness on number of fibres (top = casting side; bot. = formwork side) 
$A_{\mathrm{f}}$ is the cross-sectional area of the fibres $\left(A_{\mathrm{f}}=\pi d_{\mathrm{f}}^{2} / 4\right)$ and $A_{\text {lig }}$ is the specimen cross-section area. In Eq. (1), a random 3D fibre orientation was assumed. The orientation factor $\alpha$ for a 3D random orientation as proposed by [18, 19], are equal to 0.405 and 0.5 respectively. The theoretical values $n_{\mathrm{f}, \mathrm{t}}$ calculated using the approaches proposed by $[18,19]$ are also included in Fig. 7. The average $n_{\mathrm{f}}$ value counted in the critical planes of the specimens located in the central part of the cored cylinders (i.e. "MidTop" and "Mid-bot.") match the theoretical value calculated using the approach by [18]. Specimens close to the top surface ("Top") show an average $n_{\mathrm{f}}$ value lower than the theoretical value, whereas the average $n_{\mathrm{f}}$ value given by specimens close to the formwork side ("Bot.") is higher than the theoretical value. The average number of fibres referred to the "Bot." specimens is $73 \%$ higher than those for the "Top" specimens $\left(n_{\mathrm{f}, \text { bot }} \simeq 1.73 n_{\mathrm{f}, \text { top }}\right)$. This difference is less pronounced if specimens cored above and below the middle plane (red circles in Fig. 7) are considered. In this case, the average number of fibres for "Bot." and "Mid-bot." specimens is only 32\% higher than for the "Top" and "Mid-top" specimens, remaining in line with the results shown in Fig. 6. Results in Fig. 7 confirm that the segregation phenomenon took place during casting of the shallow beams. The large dispersion of the number of fibres is clearly visible due to the small size of the crack surface subjected to tension (1:6.25 in relation to the threepoint bending tests). The low number of detected fibres should be noted, which in part could be penalized for some fibres by the loss of the extreme part due the drilling procedure. The large dispersion of the number of fibres together with the low number of fibres detected justify the use of average values for this type of specimen. These observations agree with those found in [17] in a recent study where DEWST specimens were cored from an elevated slab.

Although the results in Fig. 7 clearly indicate that an important effect linked to a different fibre distribution influenced the samples' mechanical response in Fig. 6, it cannot be excluded that the fibre orientation effect may also have influenced the post-cracking mechanical response.

Another interesting point to be explored concerns checking segregation by using the inductive test results. The inductive test carried out at the Universitat
Politècnica de Catalunya consists of measuring the self-induction change experienced when a SFRC sample is placed inside a coil [20,21]. This method has already been applied to real-scale structures to assess fibre content and fibre orientation [22-27]. The method uses an impedance analyser which produces an electrical flow through a coil, thus inducing a magnetic field around it. If a sample is put into the coil, the ferromagnetic nature of the fibres aligned with the magnetic field increases the magnetic permeability of the medium and an inductance variation $(\Delta L)$ is measured with the analyser. Different $\Delta L$ are obtained after placing the sample into the coil in different positions. This data can be later used to predict both fibre content and fibre orientation. Further details on the analytical deductions and equations used to predict fibre content and orientation may be found in [25, 28]. The inductive method was applied to all cores prior to the DPTs. These specimens were marked with four directions of measurement $22.5^{\circ}$ apart on the cylinder bases (see Fig. 8). The inductance was measured in each of these directions as well as along the cylinder's height in order to predict its fibre distribution. As an example, Fig. 9 shows the fibre distribution measured in 8 out of the 32 specimens drilled along the $z$-axis, taken from beam F (specimens F3-top, F3-bot., F6top, F6-bot., F12-top, F12-bot., F13-top and F13-bot.).

Figure 9 shows a $360^{\circ}$ view of the inductive panorama measured or evaluated in the horizontal $x y$ plane for specimens from the same core and superimposing top and bottom samples. The specimens close to the formwork (labelled "bot." at the end of their nomenclature) record greater inductance than the specimens close with the upper surface (labelled "top" at the end of their nomenclature), thus implying a greater quantity of fibres in the former. In fact, it can be observed that the grey graphs (top samples) are almost always completely within the black graphs (bottom samples). Similar trends were found for the other specimens, but omitted here for the sake of brevity. Inductive tests show a clear tendency to segregation in both beams $\mathrm{E}$ and $\mathrm{F}$; in more than $85 \%$ of cases the grey graphs are within the black ones.

Figure 10 depicts the total inductance measured on the 32 specimens cored in the $z$-direction for the DPT with the fibre content assessed by crushing the specimens and weighing the fibres after the DPT. As described by [21, 28, 29], a linear correlation is observed between the fibre content and the inductive 


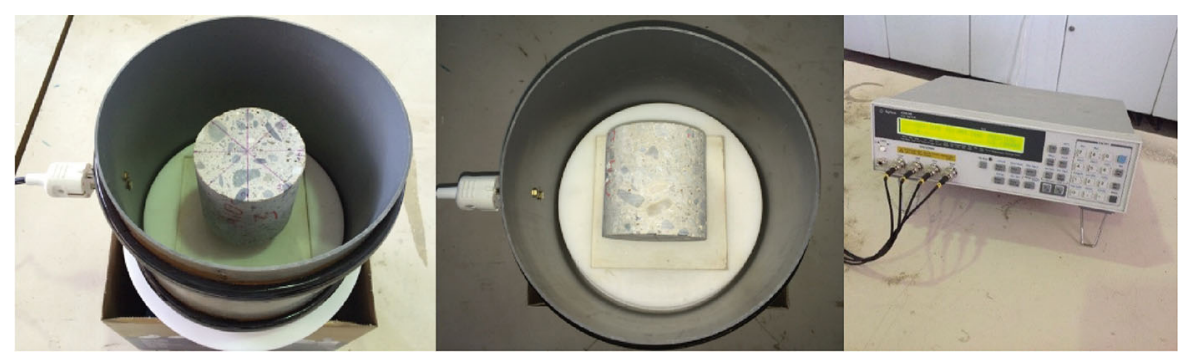

Fig. 8 Inductive test equipment and measurement
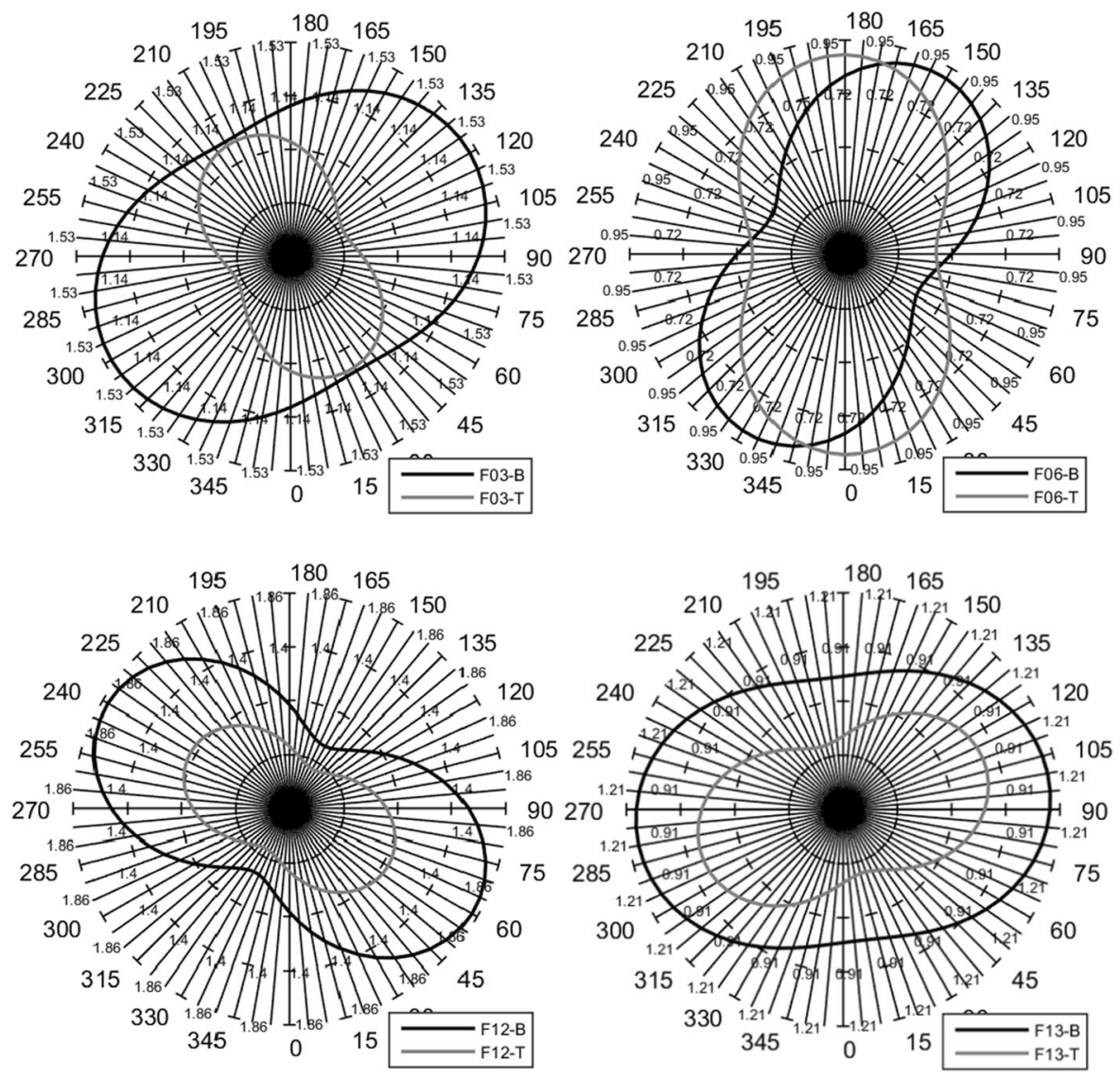

Fig. 9 Segregation effect detected using inductive tests: examples of specimens F3-top, F3-bot., F6-top, F6-bot., F12-top, F12-bot., F13-top and F13-bot. (axis indicates the angle of measurement in degrees and values in the axes indicate the inductance in $\mathrm{mH}$ )

method results. For this reason, direct measurement of the fibres' weight was done for a limited number of specimens (i.e. 4 specimens). It should be remembered that a fibre has a weight of about $0.37 \mathrm{~g}$. Figure 10 shows a clear fibre segregation since bottom specimens in general have a higher fibre content compared to the top specimens. With reference to the $32 \mathrm{DPT}$ samples cored in the $z$-direction taken from beams $\mathrm{E}$ and $\mathrm{F}$, it was found that, on average, $56 \%$ of the fibres are distributed in the lower part of the shallow beams and $44 \%$ in the upper part. The theoretical fibre quantity $m_{\mathrm{f}, \mathrm{t}}$ (in mass unit) referred to a specimen with the nominal fibre contents is also shown in Fig. 10 by a dashed black line. 


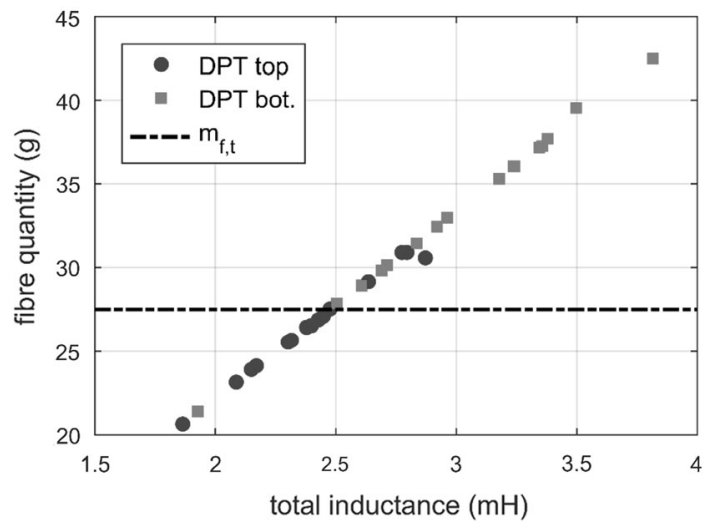

Fig. 10 Influence of DPTs specimen position within the thickness in terms of the measured quantity of fibres versus total inductance $($ top $=$ casting side bot. $=$ formwork side)

\subsection{Fibre orientation}

The fibre orientation in the hardened-state is the final result of a chain of stages that FRC passes through from mixing to hardening inside the formwork (according to [15], mainly the fresh-state properties, concrete pouring, geometry of the formwork, type of vibration and production method). Among these factors, several authors [5, 16, 19] consider the most to be the fresh state properties (especially the flowability) and the wall-effects introduced by the formworks.

The closely-linked study [4], showed that the DPT is not adequate for verifying the orientation of the fibres, given the impossibility of controlling the orientation of the cracking plane. On the other hand, the DEWST technique makes it possible to pre-assign a fracture plane. Considering that, the fibre orientation effect on mechanical performance was evaluated using DEWST results. In total, 30, 37 and 13 specimens were tested with the fracture plane perpendicular to the $x$-, $y$ - and $z$-directions, respectively. Figure 11 shows the average results of the DEWST by differentiating between specimens with different orientations of the fracture plane. The figure shows a post-peak tensile behaviour that is higher for specimens with a fracture plane orthogonal to the $x$-axis. This suggests a preferential fibre orientation along the $x$-direction (i.e. the shallow beam's longitudinal axis). Figure 11 shows that specimens tested with the fracture plane perpendicular to the $z$-direction have a

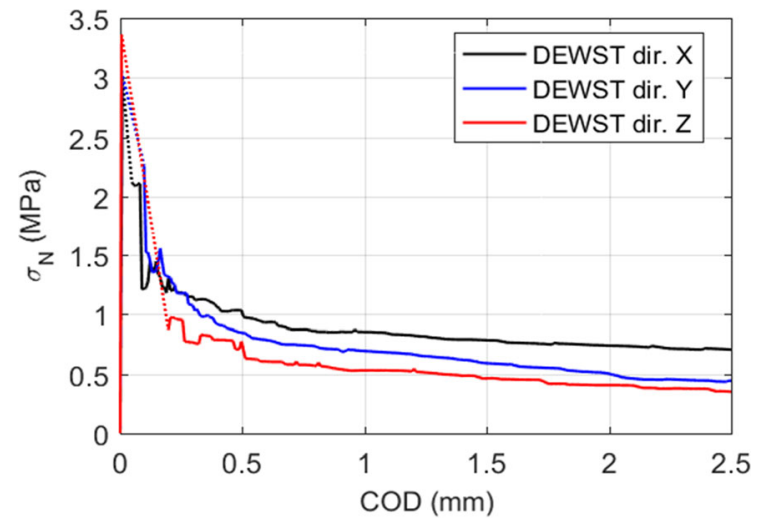

Fig. 11 Influence of the orientation of the cracked plane in the DEWSTs in terms of nominal stress versus COD

ULS residual tensile strength that is around half the highest one ( $x$-axis). A similar result was found by Mudadu et al. [30] where a ratio of residual tensile strengths of approximately 2 between specimens horizontally (corresponding to the $x$-direction in this study) and vertically (corresponding to the $z$-direction in this study) cast was obtained.

\section{Comparison between standard and non- standard tests}

The tensile constitutive curve obtained from 3PBT as prescribed by [6] and modified by [31] and those obtained from UTTs and DEWSTs are presented in Fig. 12. In order to better simulate the flexural behaviour of the beams, only the drilled core samples with their cracked planes orthogonal to the beam's $x$ axis are considered in the comparison. DPT specimens are omitted in this context since it was not possible to precisely define a cracked plane orthogonal to the beam's $x$-axis. Both UTT and DEWST average results underestimate the 3PBT constitutive law. It is worth to note that the boundary conditions of the specimens extracted by coring and their original location in the shallow beams (see Figs. 1 and 2) are different from those characterizing the notched standard beams. This justifies a different orientation of the fibres in the two cases. Following the approach proposed by [19] and confirmed also in [18], the orientation coefficient for notched beams according to EN 14651 [1], is $\alpha^{\text {RILEM }}=0.58$. On the contrary, the orientation factor for the cored specimen according to [19] is reasonably 


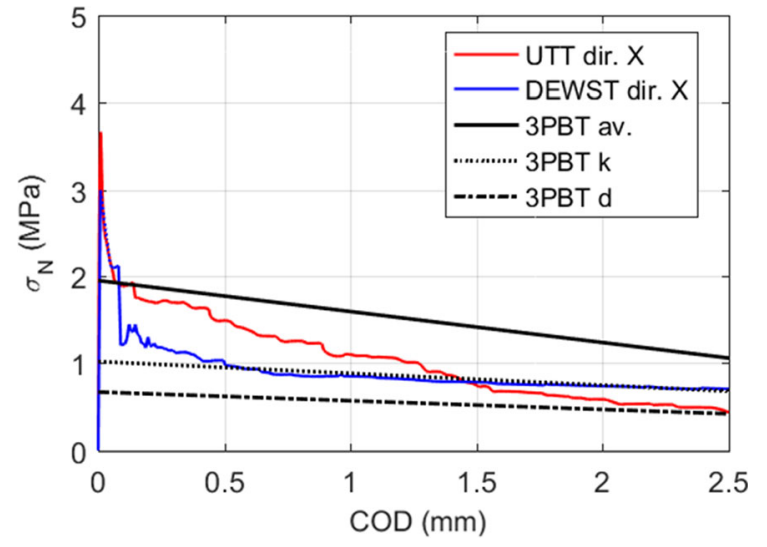

Fig. 12 Comparison of tensile constitutive equation obtained from UTTs, DEWSTs and 3PBTs

approximated by a 3D random orientation $\left(\alpha^{\mathrm{SB}}=0.5\right)$. To account for the different fibre orientation factors in the two situations (shallow beams and notched beams), the coefficient $K$ may be defined as:

$K=\frac{\alpha^{\mathrm{RILEM}}}{\alpha^{\mathrm{SB}}}=\frac{0.58}{0.5}=1.16$

Other two main aspects have to be considered. The cored specimens sacrifice a certain amount of fibres due to the extraction procedure. Fibres are $60 \mathrm{~mm}$ long and therefore a certain number of fibres passing the critical cross section and inclined at more than $20^{\circ}$ with respect to the critical section plane normal can lose their hooked end, which can therefore reduce their pull-out resistance to crack opening. Moreover, DEWST specimens were even cut along the specimen's axis to better control the crack propagation in the test: this second cut could significantly affect the pull-out resistance because the total length is only $50 \mathrm{~mm}$ compared to a fibre length of $60 \mathrm{~mm}$. It is important to observe that these reduction factors do not affect the number of fibres crossing the critical section, but only their pull-out resistance.

Looking at Fig. 12, the average curves for UTTs and DEWSTs are compared to the average uniaxial tension constitutive law identified by EN 14651 tests according to [31], the related characteristic law (assuming a normal distribution) and the design law (including the FRC strength class). The comparison between the average curves identified by means of all these notched tests highlights the fact that the average fib Model Code 2010 proposal based on EN 14651 tests is the highest one: the alignment due to formworks, the reduced number of critical sections selected (6 3PBTs against 7 UTTs and 30 DEWSTs) and the reduction of the pull-out resistance introduced by coring (UTT and DEWST) and cutting (DEWST) of the original core samples resulting in only $50 \mathrm{~mm}$ long specimens justify this result. It is worth noting that if the design curve according to fib Model Code 2010 approach is used, the curve is always on the safe side. At the same time, the average curves for DEWST, as well DPT or UTT (Fig. 4), can be regarded as a good reference for production control, especially for large crack openings, close to the ultimate value $\left(w_{\mathrm{u}}=2.5 \mathrm{~mm}\right)$ considered for Ultimate Limit States.

\section{Conclusions}

The following conclusions are derived from an analysis of the results discussed in the paper.

- The comparison of direct (UTT) and indirect (DEWST and DPT) tensile tests shows quite similar average mechanical responses. The DPT method shows the highest energy dissipation for CODs up to about $0.3 \mathrm{~mm}$ due to the formation of the conical wedge thus producing spurious energy. For CODs larger than $1.5 \mathrm{~mm}$, the specimens' response is mainly governed by the debonding and pull-out of the fibres and UTT, DEWST and DPT results show very similar trends.

- Fibre segregation was observed over the height of the shallow beams characterised using the inductive method, by fibre counting and by crushing specimens and weighing the fibres. In general, specimens located in the bottom part of the elements have higher fibre contents than those located in the top part. The differences affected the post-cracking mechanical performance of the specimens, with those located closer to the bottom providing slightly higher values than those located closer to the top (13-30\% higher residual tensile strengths). This potential segregation should be considered when designing and producing elements that rely on the fibres as the main reinforcement, such as elevated slabs reinforced only with fibres. 
- The fibre orientation's effect on the mechanical performance was evaluated using DEWSTs. In fact, the DEWST technique makes it possible to pre-assign a fracture plane which can be perpendicular to the $x$-, $y$ - and $z$-directions. Post-cracking mechanical performance of the specimens shows a post-peak tensile behaviour that is higher for specimens with a fracture plane orthogonal to the $x$-axis. This suggests a preferential fibre orientation along the $x$-direction (longitudinal direction of the shallow beams). The vertical direction $(z)$ offers a ULS residual strength that is about half the highest one (specimen oriented along the $x$-axis).

- The design constitutive law suggested in the fib Model Code 2010 approach is always on the safe side if compared to the average curves obtained from UTT, DEWST or DPT cored samples. All these techniques which are affected by coring, notching and cutting (if short samples are considered as in DEWST), can be regarded as a good tool for judging the ULS strength reliability of the FRC classified material considered.

- This study confirms the DPT (i.e. Barcelona test) as a reliable test for systematic control (quality control during production) of the tensile properties of SFRC in production, whereas DEWST appears to be effective for evaluating the effects of fibre orientation on the post-cracking strength.

Acknowledgements The authors are indebted to Prof. Roberto Felicetti for his help in conducting the uniaxial tensile tests. The authors also thank Matteo Tratta and Davide Trentini, who worked on the experimental DEWSTs and DPTs as a part of their M.Sc. thesis in Civil Engineering at Politecnico di Milano. The authors thank DSC-Erba and Calcestruzzi Erbesi for their contribution in the preparation of the specimens investigated and in sharing both material and structural design detailing.

Funding Open access funding provided by Politecnico di Milano within the CRUI-CARE Agreement.

\section{Compliance with ethical standards}

Conflict of interest The authors declare that they have no conflict of interest.

Open Access This article is licensed under a Creative Commons Attribution 4.0 International License, which permits use, sharing, adaptation, distribution and reproduction in any medium or format, as long as you give appropriate credit to the original author(s) and the source, provide a link to the Creative Commons licence, and indicate if changes were made. The images or other third party material in this article are included in the article's Creative Commons licence, unless indicated otherwise in a credit line to the material. If material is not included in the article's Creative Commons licence and your intended use is not permitted by statutory regulation or exceeds the permitted use, you will need to obtain permission directly from the copyright holder. To view a copy of this licence, visit http://creativecommons.org/licenses/by/4.0/.

\section{References}

1. EN 14651:2005+A1 (2007) Test method for metallic fibered concrete-Measuring the flexural tensile strength (limit of proportionality (LOP), residual). European Committee for Standardization (CEN), Brussels

2. di Prisco M, Ferrara L, Lamperti MGL (2013) Double edge wedge splitting (DEWS): an indirect tension test to identify post-cracking behaviour of fibre reinforced cementitious composites. Mater Struct. 46:1893-1918. https://doi.org/10. 1617/s11527-013-0028-2

3. Molins C, Aguado A, Saludes S (2009) Double punch test to control the energy dissipation in tension of FRC (Barcelona test). Mater Struct. 42:415-425. https://doi.org/10.1617/ s11527-008-9391-9

4. Martinelli P, Colombo M, de la Fuente A et al (2021) Characterization tests for predicting the mechanical performance of SFRC floors: design considerations. Mater Struct. https://doi.org/10.1617/s11527-020-01598-2

5. Abrishambaf A, Barros JAO, Cunha VMCF (2013) Relation between fibre distribution and post-cracking behaviour in steel fibre reinforced self-compacting concrete panels. Cem Concr Res. 51:57-66. https://doi.org/10.1016/j.cemconres. 2013.04.009

6. fib (2013) fib Model Code for Concrete Structures 2010. Lausanne

7. Ferrara L, Meda A (2006) Relationships between fibre distribution, workability and the mechanical properties of SFRC applied to precast roof elements. Mater Struct. 39:411-420. https://doi.org/10.1617/s11527-005-9017-4

8. Pujadas P, Blanco A, Cavalaro S et al (2014) Fibre distribution in macro-plastic fibre reinforced concrete slab-panels. Constr Build Mater. 64:496-503. https://doi.org/10. 1016/j.conbuildmat.2014.04.067

9. Kang ST, Kim JK (2011) The relation between fiber orientation and tensile behavior in an ultra high performance fiber reinforced cementitious composites (UHPFRCC). Cem Concr Res. 41(10):1001-1014. https://doi.org/10. 1016/j.cemconres.2011.05.009

10. Pujadas P, Blanco A, Cavalaro SHP et al (2014) Multidirectional double punch test to assess the post-cracking behaviour and fibre orientation of FRC. Constr Build Mater. 58:214-224. https://doi.org/10.1016/j.conbuildmat.2014. 02.023

11. Ministero delle Infrastrutture (2008) Nuove norme tecniche per le costruzioni. NTC 2008. Rome

12. Vervuurt A, Schlangen E, Van Mier JGM (1996) Tensile cracking in concrete and sandstone: part 1-basic instruments. Mater Struct. 29:9-18. https://doi.org/10.1007/ bf02486002 
13. Pujadas P, Blanco A, Cavalaro SHP et al (2013) New analytical model to generalize the Barcelona test using axial displacement. J Civ Eng Manag 19:259-271. https://doi. org/10.3846/13923730.2012.756425

14. Barnett SJ, Lataste JF, Parry T et al (2010) Assessment of fibre orientation in ultra high performance fibre reinforced concrete and its effect on flexural strength. Mater Struct. 43:1009-1023. https://doi.org/10.1617/s11527-009-9562-3

15. Laranjeira F (2010) Design-oriented constitutive model for steel fibre reinforced concrete. Universitat Politècnica de Catalunya

16. Laranjeira F, Grünewald S, Walraven J et al (2011) Characterization of the orientation profile of steel fiber reinforced concrete. Mater Struct. 44:1093-1111. https://doi. org/10.1617/s11527-010-9686-5

17. di Prisco M, Martinelli P, Parmentier B (2016) On the reliability of the design approach for FRC structures according to fib Model Code 2010: the case of elevated slabs. Struct Concr. 17(4). https://doi.org/10.1002/suco. 201500151

18. Soroushian P, Lee C-D (1990) Distribution and orientation of fibers in steel fiber reinforced concrete. ACI Mater J 87:433-439

19. Dupont D, Vandewalle L (2005) Distribution of steel fibres in rectangular sections. Cem Concr Compos. 27(3):391-398. https://doi.org/10.1016/j.cemconcomp. 2004.03.005

20. Juan-García P (2011) Evaluación no destructiva de estructuras de obra civil mediante métodos electromagnéticos. Universitat Politècnica de Catalunya

21. Torrents JM, Blanco A, Pujadas P et al (2012) Inductive method for assessing the amount and orientation of steel fibers in concrete. Mater Struct. 45:1577-1592. https://doi. org/10.1617/s11527-012-9858-6

22. Maturana A, Sanchez R, Canales J, et al (2010) Technical economic analysis of steel fibre reinforced concrete flag slabs. A real building application. In: XXXVII IAHS World Congress on Housing

23. Orbe A, Cuadrado J, Losada R, Rojí E (2012) Framework for the design and analysis of steel fiber reinforced selfcompacting concrete structures. Constr Build Mater. 35:676-686. https://doi.org/10.1016/j.conbuildmat.2012. 04.135
24. Orbe A, Rojí E, Losada R, Cuadrado J (2014) Calibration patterns for predicting residual strengths of steel fibre reinforced concrete (SFRC). Compos Part B-Eng. 58:408-417. https://doi.org/10.1016/j.compositesb.2013. 10.086

25. Blanco A, Pujadas P, De La Fuente A et al (2015) Assessment of the fibre orientation factor in SFRC slabs. Compos Part B-Eng. 68:343-354. https://doi.org/10.1016/j. compositesb.2014.09.001

26. Zhang S, Liao L, Song S, Zhang C (2018) Experimental and analytical study of the fibre distribution in SFRC: a comparison between image processing and the inductive test. Compos Struct. 188:78-88. https://doi.org/10.1016/j. compstruct.2018.01.006

27. Liao L, Cavalaro S, de la Fuente A, Aguado A (2014) Complementary use of inductive test and bending test for the characterization of SFRC. Appl Mech Mater. 580-583:2213-2219. https://doi.org/10.4028/www. scientific.net/amm.580-583.2213

28. Cavalaro SHP, López R, Torrents JM, Aguado A (2015) Improved assessment of fibre content and orientation with inductive method in SFRC. Mater Struct. 48:1859-1873. https://doi.org/10.1617/s11527-014-0279-6

29. Cavalaro SHP, López-Carreño R, Torrents JM et al (2016) Assessment of fibre content and 3D profile in cylindrical SFRC specimens. Mater Struct. 49:577-595. https://doi.org/ 10.1617/s11527-014-0521-2

30. Mudadu A, Tiberti G, Germano F et al (2018) The effect of fiber orientation on the post-cracking behavior of steel fiber reinforced concrete under bending and uniaxial tensile tests. Cem Concr Compos. 93:274-288. https://doi.org/10.1016/j. cemconcomp.2018.07.012

31. di Prisco M, Colombo M, Dozio D (2013) Fibre-reinforced concrete in fib Model Code 2010: principles, models and test validation. Struct Concr. 14:342-361. https://doi.org/ 10.1002/suco.201300021

Publisher's Note Springer Nature remains neutral with regard to jurisdictional claims in published maps and institutional affiliations. 